\title{
Critical evaluation of cloud contamination in the MISR aerosol products using MODIS cloud mask products
}

\author{
Y. Shi ${ }^{1}$, J. Zhang ${ }^{1}$, J. S. Reid ${ }^{2}$, B. Liu ${ }^{3}$, and E. J. Hyer ${ }^{2}$ \\ ${ }^{1}$ Department of Atmospheric Science, University of North Dakota, Grand Forks, ND, USA \\ ${ }^{2}$ Marine Meteorology Division, Naval Research Laboratory, Monterey, CA, USA \\ ${ }^{3}$ Department of Computer Science, University of North Dakota, Grand Forks, ND, USA \\ Correspondence to: Y. Shi (yingxi.shi@my.und.edu)
}

Received: 1 October 2013 - Published in Atmos. Meas. Tech. Discuss.: 20 November 2013

Revised: 16 April 2014 - Accepted: 23 April 2014 - Published: 23 June 2014

\begin{abstract}
Using Terra Moderate Resolution Imaging Spectroradiometer (MODIS)-based cloud screening methods, the impacts of cloud contamination on the Terra Multi-angle Imaging Spectroradiometer (MISR) aerosol optical depth (AOD) product are evaluated. Based on one year of collocated MISR and MODIS data, this study suggests that cloud contamination exists in both over-water and over-land MISR AOD data, with heavier cloud contamination occurring over the high latitude southern hemispheric oceans. On average globally, this study shows that thin cirrus cloud contamination introduces a possible $\sim 0.01$ high bias for the over-water MISR AOD retrievals. Over the mid- to high-latitude oceans and Southeast Asia, this number increases to 0.015-0.02. However, biases much larger than this mean value are found in individual retrievals, especially in retrievals that are near cloud edges. This study suggests that cloud-clearing methods using observations from MISR alone, which has only visible and near-infrared channels, may not be sufficient for all scenarios. Measurements from MODIS can be applied to assist cloud-clearing of the MISR aerosol retrievals. Cloud screening algorithms based on multi-sensor approaches are feasible and should be considered for current and future satellite aerosol studies.
\end{abstract}

\section{Introduction}

The Multi-angle Imaging Spectroradiometer (MISR) instrument has been successfully applied to observe and study atmospheric aerosols for over a decade (e.g., Kahn et al., 2005). Featuring nine unique camera angles, MISR observations have been used to retrieve aerosol optical properties over most surface types, including bright surfaces, which thwart many other passive sensors (Diner et al., 1998; Kahn et al., 2010). One of the known issues for satellite aerosol products, including the MISR aerosol products, is cloud contamination (e.g., Zhang et al., 2005; Kahn et al., 2010). Extensive research efforts been attempted to study but the impacts of cloud artifacts and cloud contamination to aerosol retrievals from other sensors, such as Moderate Resolution Imaging Spectroradiometer (MODIS) (Zhang et al., 2005; Hyer et al., 2011; Shi et al., 2011b; Toth et al., 2013) and Advanced Very High Resolution Radiometer (AVHRR) (Zhao et al., 2013), the impacts of cloud contamination on MISR aerosol products have not been fully explored or quantified. We do know that over-ocean AODs from standard operational MODIS and MISR products have positive biases as large as $0.025-0.04$, or roughly one-third of mean background AOD values (Zhang and Reid, 2010; Kahn et al., 2010). This is in stark contrast to the accuracy requirement commonly professed by climate scientists of 0.01 (CCSP, 2009) and may impact estimates of long-term aerosol trends (Zhao et al., 2013).

As suggested from previous studies, effective cloud screening for aerosol retrieval requires sophisticated algorithms and multispectral visible and infrared radiance data (e.g., Remer et al., 2005). However, MISR lacks channels in the near- and far-infrared region where cirrus clouds are most easily detected. The operational cloud screening algorithm for MISR AOD products is based on cloud-induced perturbations in either spectral radiance or angular-dependent radiance values with the assistance of a reflected layer height 
technique (e.g., Kahn et al., 2007). Note that the operational MISR cloud screening method does not fully exploit the MISR data for aerosol-related applications. For example, Pierce et al. (2010) show, with their research algorithm, that MISR can retrieve thin cirrus with optical depth below $\sim 0.3$ under favorable conditions. A recent study by Witek et al. (2013) has extended the cloud screening effort by requiring $60 \%$ clear pixels for every MISR AOD retrieval using a $1.1 \mathrm{~km}$ resolution clear flag that is included in the MISR aerosol products. Using the Witek et al. (2013) method, MISR AODs are reduced by 0.04 with an $85 \%$ data loss rate, and the averaged MISR AODs are in line with the Navy MODIS data assimilation grade product. However, cloud detection may be incomplete with the use of only visible and near-IR channels, especially for thin clouds over bright surfaces. On board the same satellite platform as MISR, MODIS has a total of 36 spectral channels, including cirrus cloudsensitive channels as well as infrared channels, which provide an enhanced capability of detecting the presence of clouds in an observed scene (e.g., Ackerman et al., 1998). Previously published study of cloud contamination in the MISR retrieved AOD have not yet taken advantage of collocated Terra-MODIS cloud masking data. In this study, level 2 cloud mask products from Terra MODIS were used to evaluate the cloud contamination in the Terra MISR aerosol products and evaluate different methods for eliminating cloud contamination from MISR aerosol products.

\section{Data and methodology}

\subsection{Aerosol Robotic Network (AERONET) sun photometer data}

The Aerosol Robotic Network (AERONET) is a federated network of sun photometer instruments deployed in several hundred locations across the globe. The AERONET sun photometers measure solar irradiance at multiple wavelengths, and can be used for very accurate estimates of AOD, as well as additional aerosol optical properties. With a reported uncertainty of 0.015 , the AERONET AOD data are commonly used as a benchmark for validating satellite aerosol retrievals (Holben et al., 1998). For this study, 7 years (2001-2007) of level 2 AERONET data were used.

\subsection{MISR aerosol products}

MISR measures radiance in 4 spectral bands in the visible and near-infrared $(446.4,557.5,671.7$, and $866.4 \mathrm{~nm})$, with 9 cameras pointed at different angles along the subsatellite track. Version 22 MISR aerosol products include AOD, aerosol particle size and shape, as well as other ancillary data at a spatial resolution of $17.6 \mathrm{~km} \times 17.6 \mathrm{~km}$. Validated against AERONET data, uncertainties in the MISR AOD product are on the order of 0.05 or $0.2 \times$ AOD $_{\text {AERONET }}$ (e.g., Kahn et al., 2005). Cloud contamination in the MISR
AOD data has been mentioned (Kahn et al., 2010), but has not been fully investigated using means like the MODIS cloud masking data. The baseline quality assessment steps (referred as "self-QAed" hereafter) in this study are based on data included in the MISR aerosol products (Kahn et al., 2009; Bull et al., 2010). The following filters are used for the "Self-QAed" data sets:

- The Retrieval Applicability Mask flag $(=0)$ is used to identify pixels free of cloud, glint, and other factors.

- The Regional Classification Indicator $(=0)$ is used for selecting retrievals above clear background region.

- The Aerosol Retrieval Success Flag (=7) is used to identify successful retrievals.

- The Regional Surface Type Indicator is used to separate over-land from over-water retrievals; and also to exclude potential problematic regions such as shallow/coastal waters and Polar regions.

Note that within the MISR AOD product, a retrieval applicability mask is available at a $1.1 \mathrm{~km}$ resolution, for nine camera angles and four spectral bands. Only the red and nearIR bands are used for over-water aerosol retrievals (Martonchik et al., 1998). This mask is in a much finer resolution than the $17.6 \mathrm{~km}$ AOD retrievals and includes environmental conditions such as "clear", "glitter-contaminated", "cloudy" and "topographically obscured". Using the clear indicator in the retrieval applicability mask, a clear flag fraction (CFF) can be calculated for each of the MISR AOD retrievals by taking the ratio of clear versus total flags for a total of $16 \times 16 \times 9$ flags ( 9 angles, $16 \times 16$ MISR pixels at $1.1 \mathrm{~km}$ ). Witek et al. (2013) discussed the possibility of using the MISR CFF (use CFF $>60 \%$ ) as a means of removing cloud-contaminated MISR AOD retrievals. The MODISbased MISR cloud screening method developed from this study was compared to the method included in Witek et al. (2013). The results are shown in Sect. 3.0.

The impacts of cloud contamination on the MISR aerosol product were evaluated using 7 years (2001-2007) of collocated AERONET, MODIS and MISR data sets. One year of collocated MODIS and MISR products (2007) were also used for evaluating various cloud masking methods spatially. MISR AOD scenes were collocated with AERONET data following the method presented in Zhang and Reid (2006). Pairs of observations were recorded when the spatial distance between the MISR and AERONET data is within $0.3^{\circ}$ (latitude/longitude), and the temporal difference is within \pm 30 min. The collocated MISR and AERONET data were further collocated with MODIS cloud mask data for the cloud-clearing analysis for the MISR aerosol products (see Sect. 2.4). 


\subsection{Cloud screening methods using MISR data}

The MISR cloud team has developed three independent cloud detection methods: Radiometric Camera-by-Camera Cloud Mask (RCCM), Stereoscopically Derived Cloud Mask (SDCM), and Angular Signature Cloud Mask (ASCM) (Diner et al., 1998; Martonchik et al., 2009). RCCM is based on a radiance threshold technique and produces cloud masks for each of the nine camera angles at a $1.1 \mathrm{~km}$ spatial resolution. The SDCM method is designed to retrieve the reflecting layer height, and is used, in combination with the RCCM method, to indicate the confidence level of clouds near or above a surface. The ASCM method utilizes the differences in angular-dependent Rayleigh scattering in the blue and red or near-IR channels at forward-scattering directions between high clouds and the surface. It is designed for detecting high clouds and for clouds over ice and snow surfaces. Over land, ASCM is only applied over the ice and snow surfaces with static thresholds at this moment. A sensitivity study showed that the ASCM method is not sensitive to cirrus clouds that have optical depths less than 0.5 (Di Girolamo and Davies, 1994).

Besides the three primary cloud detection methods mentioned above, two additional data-filtering procedures, angleto-angle smoothness evaluation and angle-to-angle correlation evaluation, along with a brightness test, are also used to further remove possible contaminated observations for aerosol retrievals by the MISR aerosol team (Diner et al., 2001; Martonchik et al., 2002). Both methods are aimed to eliminate pixels with large radiance variations within each camera angle and among the nine camera angles.

\subsection{Cloud screening methods using MODIS data}

The MODIS instrument has a total of 36 spectral channels with spatial resolutions ranging from 250 to $1000 \mathrm{~m}$. With additional channels centered at IR and the $1.375 \mu \mathrm{m}$ channels, MODIS, in comparison with MISR, has an enhanced capability of detecting the presence of clouds, especially thin cirrus (Ackerman et al., 1998). The MODIS cloud mask products focus on representing a level of confidence of how unobstructed the satellite field of view is at the pixel level. A combination of 19 visible and infrared spectral bands is used to perform a series of threshold and consistency tests to detect clouds. The MODIS MOD35 cloud mask indicates cloud status with one of four values, including "cloudy" (CD), "uncertain clear" (UC), "probably clear" (PC), and "confidently clear" (CC), at a $1 \mathrm{~km}$ resolution (Frey et al., 2008). The MODIS cloud mask products also include other ancillary information such as detection of thin cirrus and high clouds, surface shadow, cloud adjacency, sea ice, snow, and sun glint. In this study, collocated with the MISR aerosol products, the $1 \mathrm{~km}$ resolution cloud screening flags from the MODIS cloud mask products were used for cloud clearing of MISR scenes. The thin cirrus cloud flag, derived primarily from the $1.375 \mu \mathrm{m}$ water vapor sensitive band (Gao et al., 2002; Gao and Kaufman, 2003), was also used in this study for detecting thin cirrus clouds. Ackerman et al. (2008) showed that cloud/clear areas from the MODIS cloud mask products agree with lidar data about $85 \%$ of the time with a cloud optical depth sensitivity of $\sim 0.4$. Uncertainties in the MODIS cloud mask products as well as the complicated nature of near cloud aerosols contribute to the complexity of the cloudclearing issue. For example, particle hydration (Tackett and Di Girolamo, 2009) and/or cloud particle detrainment might occur near clouds, which make it ambiguous in discriminating clouds and aerosols.

The spatial resolution of the MODIS cloud masking data is $1 \mathrm{~km}$. However, the geo-location data in the Terra MODIS cloud mask products have a spatial resolution of $5 \mathrm{~km}$. Therefore, to speed up the processing time, the cloud mask data were first averaged to a $5 \mathrm{~km} \times 5 \mathrm{~km}$ resolution, providing occurrence ratio for each cloud status. The $5 \mathrm{~km} \times 5 \mathrm{~km}$ Terra MODIS cloud masking data were then collocated with the Terra MISR aerosol products, with the spatial and temporal differences between the two products set to $6 \mathrm{~km}$ and $30 \mathrm{~min}$, respectively. The spatial resolution for the Terra MISR aerosol retrievals is $\sim 17.6 \mathrm{~km}$, thus one MISR aerosol retrieval can be collocated with multiple MODIS cloud masking values. The occurrence ratios from the $5 \mathrm{~km}$ averages were further averaged to compute a total of four parameters for one MISR AOD retrieval: cloudy fraction $\left(F_{\mathrm{cd}}\right)$, uncertain clear fraction $\left(F_{\mathrm{uc}}\right)$, probably clear fraction $\left(F_{\mathrm{pc}}\right)$, and confidently clear fraction $\left(F_{\mathrm{cc}}\right)$. The collocated thin cirrus cloud flag was processed the same way to construct an additional parameter that represents the fraction of the thin cirrus cloud-free regions at the MISR AOD resolution ( $\left.F_{\text {cirrus_free }}\right)$.

Lastly, 7 years (2001-2007) of collocated MISR and AERONET aerosol, as well as MODIS cloud mask products, were used to evaluate the impacts of various cloud screening methods on the MISR AOD retrievals. One year of collocated Terra MISR aerosol and MODIS cloud mask products were used to investigate the impacts spatially.

\section{Results: a case study}

An example of potential cloud contamination in the MISR aerosol products is shown in Fig. 1, over remote southern oceans $\left(\sim 44^{\circ}\right.$ to $52^{\circ} \mathrm{S}$ and $124^{\circ}$ to $136^{\circ} \mathrm{W}$, on $3 \mathrm{Jan}-$ uary 2007), where a pristine marine environment is expected. Figure 1a shows the RGB image constructed using nadirviewing MISR near-IR, green and blue bands. Cloudy and clear regions are observed in the bottom and upper parts of Fig. 1a, respectively. Figure $1 \mathrm{~b}$ is the corresponding MISR self-QAed AOD plot with AOD values ranging from near zero to over one. The nearly homogeneous low AODs of less than 0.1 are found from cloud-free oceans. Near cloud edges and within cloudy regions, AODs of $0.2-0.3$ are more typically found. To better illustrate the relative location between 

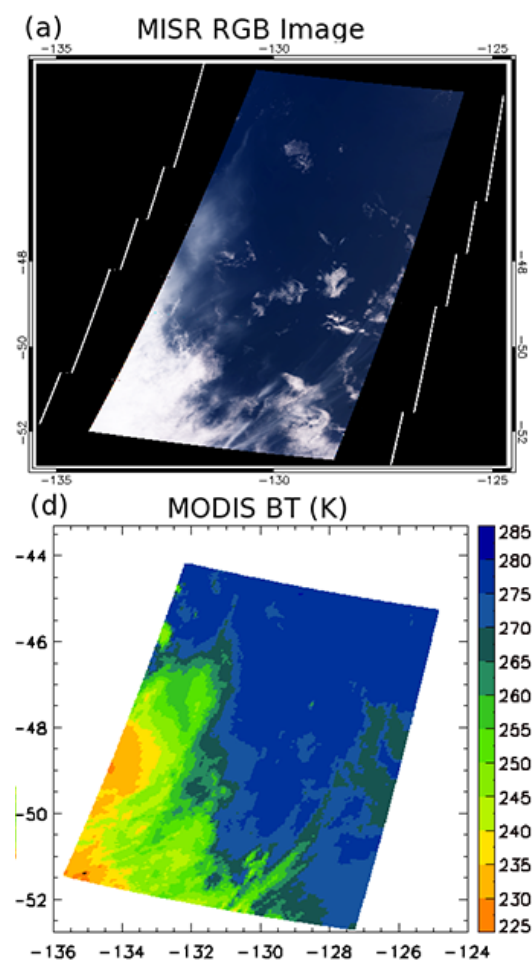

(g) Collocated MODIS Fpc

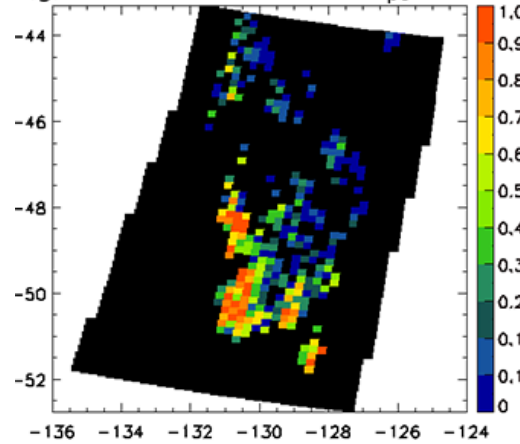

(j) MISR CFF

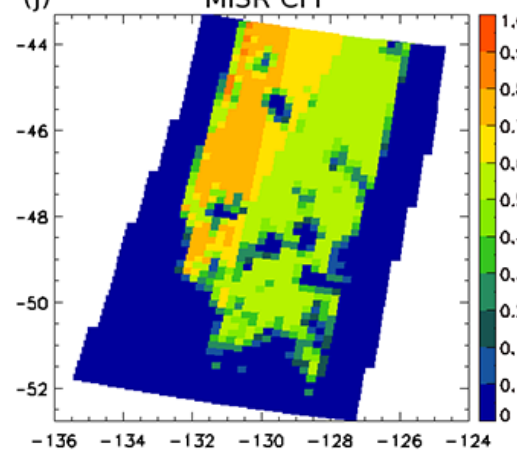

(b) MISR AOD $(0.558 \mu \mathrm{m})$

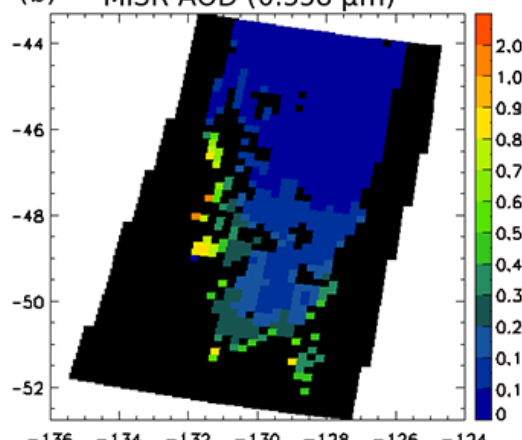

(e) MODIS Cloud Mask

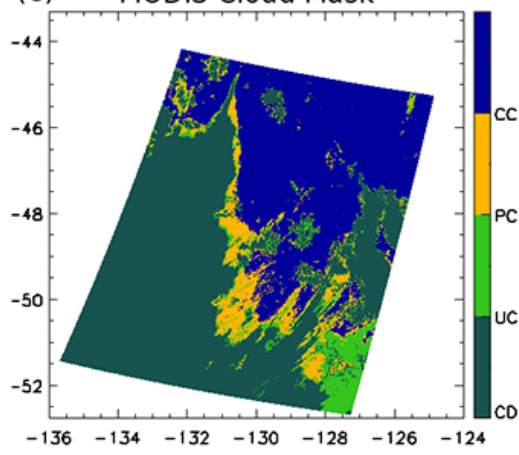

(h) MISR AOD after $\mathrm{F}_{\mathrm{cd}}+\mathrm{F}_{4 \mathrm{c}}$ filtering (c) MISR AOD overlay RGB

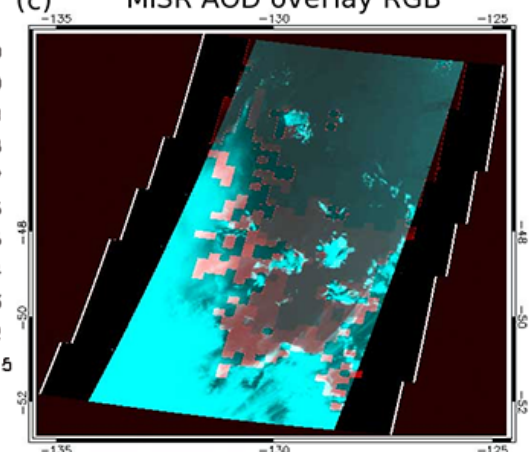

(f) Collocated MODIS F no_thin_cirrus

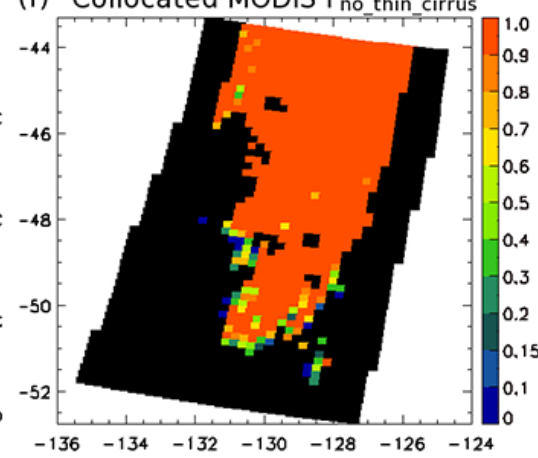

(i) MISR AOD after $F_{c c}$ filtering
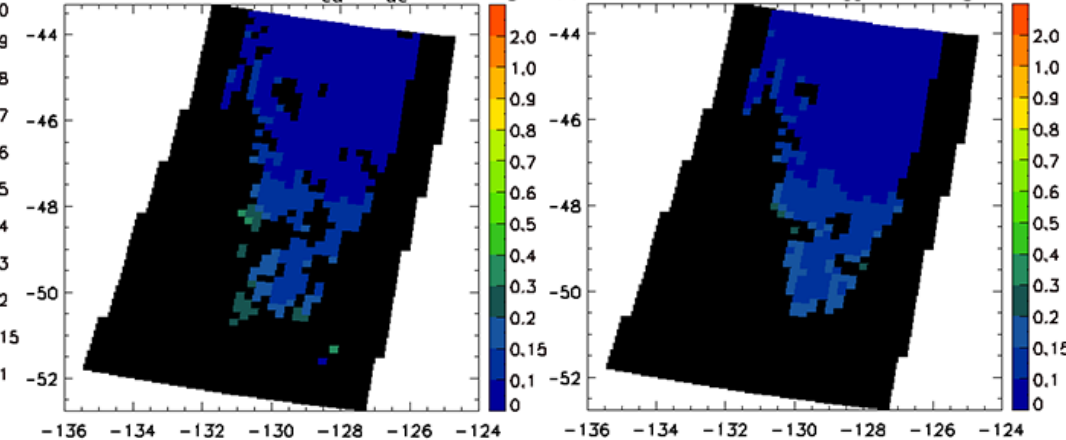

(k) MISR AOD after CFF filtering

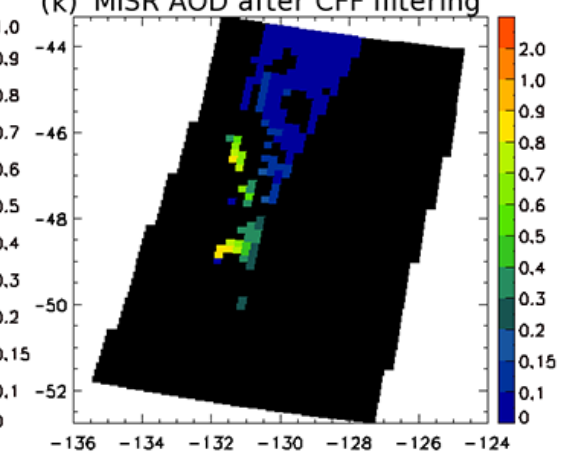

Figure 1. A case study on 3 January 2007 , over the remote oceans ( $44^{\circ}$ to $52^{\circ} \mathrm{S}$ and $124^{\circ}$ to $136^{\circ} \mathrm{W}$ ), (a) RGB image created using the MISR Near-IR, green and blue bands, (b) MISR self-QAed AOD over the case study region, (c) Overlay of (a) on (b) where the intensity of red is correlated with the magnitude of the AOD, (d) MODIS brightness temperature (BT), (e) MODIS cloud mask, (f) collocated MODIS thin cirrus-free cloud fraction $\left(F_{\text {cirrus_free }}\right)$ in MISR AOD domain, (g) similar to (f) but for the collocated MODIS probably clear fraction $\left(F_{\mathrm{pc}}\right)$, (h) MISR AOD after passing the MODIS cloudy fraction $\left(F_{\mathrm{cd}}\right)<10 \%$ and the MODIS uncertainty clear fraction $\left(F_{\mathrm{uc}}\right)<20 \%$ cloud filters, (i) MISR AOD after passing the MODIS confident clear fraction $\left(F_{\mathrm{cc}}\right)>20 \%$ cloud filter, $(\mathbf{j})$ MISR clear flag fraction $(\mathrm{CFF})$, and (k) MISR AOD after passing the MISR CFF $>60 \%$ filtering. 
cloud edges and the retrieved AODs, Fig. 1c was created by overlaying Fig. 1a (in aqua color) and Fig. 1b (in red color) in a false-color composite. Bright red colors indicate high AOD values. Most of the highest AOD retrievals (AODs greater than 0.3 ) are located within cloudy regions and higher AOD values of around 0.2 to 0.3 are found near the edge of clouds. Figure 1d shows the MODIS brightness temperature (BT) at a $5 \mathrm{~km}$ resolution. Retrievals that have AOD values above 0.8 are found within regions that have BT values lower than $255 \mathrm{~K}$, a clear indication of cloud contamination. Figure 1e shows the MODIS cloud mask data at a $1 \mathrm{~km}$ resolution with each pixel flagged as one of the four cloudy conditions: CD, UC, PC, and CC. Regions with high AOD values are mostly associated with pixels that have PC, UC, or CD cloud flags. This concept is further demonstrated in Fig. 1f-i. Figure 1f shows the fraction of MODIS cloud mask data that are free from thin cirrus cloud contamination $\left(F_{\text {cirrus_free }}=100 \%\right)$, averaged in the MISR AOD resolution. Most thin cirrus cloud-free regions $\left(F_{\text {cirrus_free }}=100 \%\right)$ are associated with low MISR AOD values of $\sim 0.15$ or less. Figure $1 \mathrm{~g}$ is similar to Fig. 1f, but was created using the PC flag. High AOD values of $0.2-0.3$ are still observed when $F_{\mathrm{pc}}$ is set to above 0.8 , suggesting that the PC flag may not be a good cloud-free sky indicator. Using stringent threshold values of $F_{\mathrm{cd}}$ and $F_{\mathrm{uc}}\left(F_{\mathrm{cd}}<10 \%\right.$ and $\left.F_{\mathrm{uc}}<20 \%\right)$, Fig. $1 \mathrm{~h}$ shows that most of the AODs larger than 0.3 are removed, although there are still some AODs around 0.3 located between clouds in the bottom right of the image. Figure 1i shows the cloud clearing with the use of the $F_{\mathrm{cc}}$ filter $\left(F_{\mathrm{cc}}>20 \%\right)$, most high AOD retrievals are removed, showing that the $F_{\mathrm{cc}}$ filter can be effectively used for cloud screening of MISR data. Attempts were also made to filter out cloud contamination in the MISR AOD data using the MISR CFF data (Fig. $1 \mathrm{j}$ and $\mathrm{k}$ ). The fraction of the clear flag within the scene is shown in Fig. 1j. Figure 1k shows the MISR AOD retrievals after applying the MISR CFF filter (CFF $>60 \%$ ) as used in Witek et al. (2013). Shown in Fig. 1k, high AOD retrievals at the bottom right of the image are removed, including a significant portion of cloud-free AODs as identified by MODIS, causing a $75 \%$ data loss. More importantly, some of the high AODs, located within the totally cloudy regions as seen from Fig. 1c, passed the MISR CFF filter. This case study suggests that the MISR CFF method can be used to remove cloud-contaminated MISR AOD data, but may not be as effective as the MODIS-based method, and incurs a cost of significant data loss. Thus, MODIS $F_{\mathrm{cc}}$ is the primary parameter used in the remainder of this study for cloud-clearing of the MISR AOD retrievals. Shown from this case study, cloud contamination exists in MISR aerosol products, and MODIS cloud mask data can be used, effectively, to exclude most of the cloud contaminated MISR AOD data points, especially with the use of the MODIS $F_{\mathrm{cc}}$ filter. Still readers should be aware that there are uncertainties in cloud masking itself and such issues are discussed later in the Recommendations and Conclusions section.

\subsection{Cloud screening using the MODIS cloud mask products}

A statistical analysis was conducted to explore the relationships between the four fractional parameters derived from the MODIS cloud mask products $\left(F_{\mathrm{cd}}, F_{\mathrm{uc}}, F_{\mathrm{pc}}\right.$, and $\left.F_{\mathrm{cc}}\right)$ and MISR AOD. Shown in Fig. 2 are the means, medians, and data distributions of MISR AOD values as functions of $F_{\mathrm{cd}}$, $F_{\mathrm{uc}}, F_{\mathrm{pc}}$, and $F_{\mathrm{cc}}$ for both the over-water (Fig. 2a to d) and over-land (Fig. 2e to h) cases using collocated MISR AOD and MODIS cloud mask data for 2007, with the fractional data density illustrated in color contours for every $10 \%$ of a given fraction. The fractional data density is the contour of the number of pixels for every 0.02 MISR AOD and every $10 \%$ cloud fraction over the total number of pixels within the corresponding $10 \%$ cloud fraction. Notice that fractional values of $F_{\mathrm{cd}}, F_{\mathrm{uc}}, F_{\mathrm{pc}}$, and $F_{\mathrm{cc}}$ indicate the probability of occurrence. For example, an increase of $F_{\mathrm{cd}}$ from 0 to $100 \%$ indicates a change from an unknown cloudy or clear scene to a $100 \%$ high confident cloudy scene (or low confident cloudy in case of $F_{\mathrm{uc}}$ ), while an increase of $F_{\mathrm{cc}}$ from 0 to $100 \%$ means a change from an unknown scene to a $100 \%$ high confident clear scene (or low confident clear in case of $\left.F_{\text {pc }}\right)$. In Fig. 2a, the mean and median MISR AODs show a decreasing trend as $F_{\mathrm{cc}}$ (e.g., percentage of clear regions) increases. In comparison, Fig. $2 \mathrm{~d}$ shows an increasing trend in MISR AOD as $F_{\text {cd }}$ (confident cloudy fraction) increases. Both Fig. 2a and d show a similar feature as that found in the MODIS Dark Target (DT) AOD data, a feature identified by Zhang et al. (2005) as cloud contamination in the MODIS DT aerosol products. Mixed information is shown in Fig. 2b $\left(F_{\mathrm{pc}}\right)$ and Fig. $2 \mathrm{c}\left(F_{\mathrm{uc}}\right)$ when the detection of cloud and clear scenes is less certain, indicating that PC and UC flags are not good for use in cloud masking of MISR data. Figure 2e$\mathrm{h}$ show a similar analysis as Fig. 2a-d but for the over-land case. Again, decreasing/increasing trends are found for the $F_{\mathrm{cc}} / F_{\mathrm{cd}}$ cases. Comparing the over-land mean MISR AOD at a confident clear sky $\left(F_{\mathrm{cc}}=100 \%\right.$, Fig. $\left.2 \mathrm{e}\right)$ with the similar scenario for the over-water case (Fig. 2a), a higher mean AOD value of 0.18 is found for the over-land case. In comparison, increasing $F_{\mathrm{uc}}$ and $F_{\mathrm{cd}}$ percentages to $100 \%$ raises the over-land MISR AOD to values over 0.3 and 0.4 , a clear indication of cloud contamination in the MISR AOD data. Suggested from Fig. 2, it is feasible to use $F_{\mathrm{cc}}$ for cloud filtering of the MISR aerosol products.

Using 7 years of collocated MODIS, MISR and AERONET data (2001-2007), a sensitivity study was conducted to investigate different cloud filtering methods using $F_{\mathrm{cd}}, F_{\mathrm{uc}}, F_{\mathrm{pc}}$, and $F_{\mathrm{cc}}$. Tables 1 and 2 show the root mean square errors (RMSEs), the mean absolute error (MAE) of MISR AOD (validated against AERONET data), and the fraction of data within the expected uncertainty range $\left(0.05\right.$ or $\left.0.2 \times \mathrm{AOD}_{\mathrm{AERONET}}\right)$ (e.g., Kahn et al., 2010) for 12 cloud-filtering steps for over-ocean and over-land cases, respectively. 

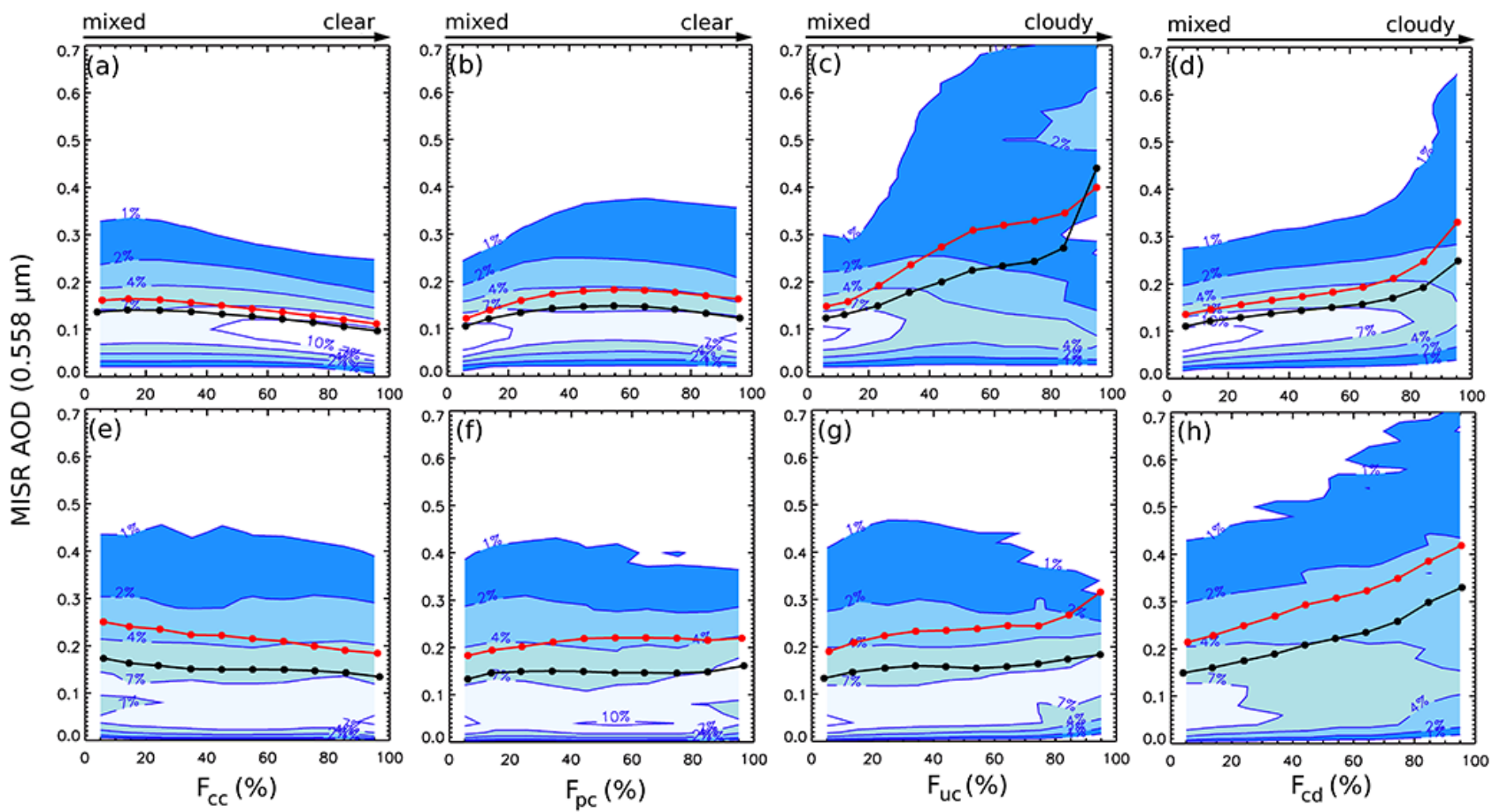

Figure 2. MISR AOD as functions of the percentage of occurrences of the cloud flags from the MODIS cloud mask products: (a, e) confident clear fraction $\left(F_{\mathrm{cc}}\right),(\mathbf{b}, \mathbf{f})$ probably clear fraction $\left(F_{\mathrm{pc}}\right),(\mathbf{c}, \mathbf{g})$ uncertainty clear fraction $\left(F_{\mathrm{uc}}\right)$ and $(\mathbf{d}, \mathbf{h})$ cloudy fraction $\left(F_{\mathrm{cd}}\right) .(\mathbf{a})$ to $(\mathbf{d})$ are for the over-water data and (e) to (h) are for the over-land data. The color contour represents the fractional data density for every $10 \%$ cloud fraction. The red and black dots represent the mean and median MISR AOD values within a $10 \%$ cloud fraction bin, respectively.

The RMSE is defined as

$\mathrm{RMSE}=\sqrt{\frac{1}{n} \sum_{n}\left(\mathrm{AOD}_{\mathrm{AERONET}}-\mathrm{AOD}_{\mathrm{MISR}}\right)^{2}}$

The MAE is defined as

$\mathrm{MAE}=\frac{1}{n} \sum_{n}\left(\left|\mathrm{AOD}_{\mathrm{AERONET}}-\mathrm{AOD}_{\mathrm{MISR}}\right|\right)$.

The 12 scenarios are self-QAed, $F_{\mathrm{cd}}<50 \%, F_{\mathrm{cd}}>50 \%$, $F_{\mathrm{uc}}<50 \%, F_{\mathrm{uc}}>50 \%, F_{\mathrm{cc}}>20 \%, F_{\mathrm{cc}}>50 \%, F_{\mathrm{cc}}>$ $80 \%$, three $F_{\text {cc }}$ cloud-filtering steps combined with the cirrus cloud filter $\left(F_{\text {cirrus free }}=100 \%\right)$, and cirrus cloud free $\left(F_{\text {cirrus_free }}=100 \%\right)$. There are two types of data loss rates presented. One is calculated based on the collocated MISR and AERONET data and another is recorded using all available MISR AOD data in 2007. The data loss rates are not reported for $F_{\mathrm{uc}}$ and $F_{\mathrm{cd}}$ cases simply because $F_{\mathrm{uc}}$ and $F_{\mathrm{cd}}$ are not used for cloud clearing of the MISR aerosol products. Using the $F_{\mathrm{cd}}>50 \%$ filter, an increase of more than $60 \%$ in RMSE is found for MISR AOD retrievals over both land and ocean with $20 \%$ less data that fall within the expected error range. Even for the $F_{\mathrm{uc}}>50 \%$ filter, a $20 \%$ increase in RMSE is shown globally, indicating that cloud contamination is physically identifiable in the MISR AOD data, causing a high bias to the AOD retrievals (also discussed later in the text). Note that AERONET data may also be impacted by the thin cirrus contamination (Chew et al., 2011).

For the over-ocean case, when increasing the $F_{\mathrm{cc}}$ filtering values from $20 \%$ to $80 \%$ with the cirrus-free filter, a reduction in RMSE (compared to the self-QAed case) from $15 \%$ to $27 \%$ is found along with an increase in the fraction of data that falls within the expected error range. An approximately 0.006 decrease in bias (validated against AERONET) is observed with a $30 \%$ data loss. A larger bias reduction is expected in cloudy regions, which is critical to aerosol modeling studies. For aerosol forcing studies, a 0.006 decrease in bias is welcomed, as the required accuracy of AOD for aerosol forcing studies is 0.01 (CCSP, 2009). Over global land, increasing the $F_{\mathrm{cc}}$ filtering values from $20 \%$ to $80 \%$ with the cirrus-free filter introduces an increase in RMSE reduction from $16 \%$ to $24 \%$, but with an increasing data loss rate from 15 to $27 \%$ for all MISR AOD data. Negligible effects are found over land for increasing $F_{\mathrm{cc}}$ from 20 to $50 \%$. This may be caused by less data available within this $F_{\mathrm{cc}}$ range. Also, the RMSE and MAE values have insignificant changes after using the thin cirrus filter for the over land case. It may be possible that the MODIS cirrus cloud mask is not sensitive to cirrus clouds under certain circumstances (for example, COD < 0.3) (Sassen and Cho, 1992). 
Table 1. The RMSE, the MAE, the fraction of data within the expected error $(0.05$ or $20 \%$ of AOD $\mathrm{AERONET})$, and the data loss rates (both for the MISR AOD data that are collocated with AERONET data and for all MISR AOD data) under 12 conditions over oceans. $F_{\text {cd }}$ is the cloudy fraction, $F_{\mathrm{uc}}$ is the uncertainty clear fraction, and $F_{\mathrm{cc}}$ is the confident clear fraction. The thin cirrus cloud filter refers to thin cirrus cloud free (set $F_{\text {cirrus_free }}=100 \%$ ) as detected by MODIS. The percentages of data loss are presented and the numbers enclosed in the parentheses are the total number of the paired data that passed the data screening criteria.

\begin{tabular}{lrrrrr}
\hline & RMSE & MAE & $\begin{array}{r}\% \text { within the } \\
\text { expected error }\end{array}$ & $\begin{array}{r}\text { Data loss and number of cases } \\
\text { (collocated with AERONET) }\end{array}$ & $\begin{array}{r}\text { Data loss } \\
\text { (all MISR AOD data) }\end{array}$ \\
\hline Self-QAed & 0.082 & 0.059 & $59 \%$ & $0 \%(2091)$ \\
$F_{\mathrm{cd}}<50 \%$ & 0.080 & 0.056 & $60 \%$ & $7 \%(1936)$ \\
$F_{\mathrm{cd}}>50 \%$ & 0.137 & 0.107 & $40 \%$ & $93 \%(155)$ \\
$F_{\mathrm{uc}}<50 \%$, & 0.084 & 0.059 & $60 \%$ & $1 \%(2070)$ \\
$F_{\mathrm{uc}}>50 \%$, & 0.096 & 0.081 & $43 \%$ & $99 \%(21)$ \\
$F_{\mathrm{cc}}>20 \%$ & 0.073 & 0.053 & $61 \%$ & $27 \%(1527)$ \\
$F_{\mathrm{cc}}>50 \%$ & 0.068 & 0.050 & $63 \%$ & $37 \%(1312)$ \\
$F_{\mathrm{cc}}>80 \%$ & 0.063 & 0.047 & $65 \%$ & $51 \%(1019)$ \\
$F_{\mathrm{cc}}>20 \%+$ thin cirrus cloud filter & 0.070 & 0.050 & $63 \%$ & $36 \%(1328)$ \\
$F_{\mathrm{cc}}>50 \%+$ thin cirrus cloud filter & 0.065 & 0.048 & $65 \%$ & $44 \%(1177)$ \\
$F_{\mathrm{cc}}>80 \%+$ thin cirrus cloud filter & 0.060 & 0.046 & $66 \%$ & $54 \%(952)$ \\
Thin cirrus cloud filter & 0.076 & 0.054 & $62 \%$ & $22 \%(1636)$ \\
\hline
\end{tabular}

Table 2. Similar to Table 1 but for the over-land case.

\begin{tabular}{lcrrrr}
\hline & RMSE & MAE & $\begin{array}{r}\text { \% within the } \\
\text { expected error }\end{array}$ & $\begin{array}{c}\text { Data loss and number of cases } \\
\text { (collocated with AERONET) }\end{array}$ & $\begin{array}{c}\text { Data loss } \\
\text { (all MISR AOD data) }\end{array}$ \\
\hline Self-QAed & 0.143 & 0.072 & $61 \%$ & $0 \%(9326)$ \\
$F_{\mathrm{cd}}<50 \%$ & 0.136 & 0.136 & $62 \%$ & $3 \%(9016)$ \\
$F_{\mathrm{cd}}>50 \%$ & 0.262 & 0.144 & $42 \%$ & $97 \%(310)$ \\
$F_{\mathrm{uc}}<50 \%$, & 0.136 & 0.069 & $62 \%$ & $1 \%(9219)$ \\
$F_{\mathrm{uc}}>50 \%$, & 0.400 & 0.189 & $47 \%$ & $99 \%(107)$ \\
$F_{\mathrm{cc}}>20 \%$ & 0.123 & 0.067 & $62 \%$ & $13 \%(8160)$ \\
$F_{\mathrm{cc}}>50 \%$ & 0.121 & 0.065 & $63 \%$ & $18 \%(7639)$ \\
$F_{\mathrm{cc}}>80 \%$ & 0.113 & 0.061 & $65 \%$ & $32 \%(6352)$ \\
$F_{\mathrm{cc}}>20 \%+$ thin cirrus cloud filter & 0.120 & 0.066 & $63 \%$ & $25 \%(7039)$ \\
$F_{\mathrm{cc}}>50 \%+$ thin cirrus cloud filter & 0.118 & 0.064 & $64 \%$ & $28 \%(6706)$ \\
$F_{\mathrm{cc}}>80 \%+$ thin cirrus cloud filter & 0.109 & 0.060 & $65 \%$ & $38 \%(5765)$ \\
Thin cirrus cloud filter & 0.143 & 0.070 & $62 \%$ & $20 \%(7432)$ \\
\hline
\end{tabular}

Figure 3 shows the spatial distributions of MISR AOD for year 2007 at a half-degree lat/lon resolution, using the selfQAed MISR data (Fig. 3a) and the MISR AOD after applying the $20 \%$ and $80 \% F_{\text {cc }}$ cloud filters combined with the thin cirrus cloud filter $\left(F_{\text {cirrus_free }}=100 \%\right)($ Fig. $3 \mathrm{~b}$ and $\mathrm{c})$. Although the overall patterns are similar, differences are also visible (Fig. 3e and f). For example, the aerosol belt over the high-latitude southern oceans from Fig. $3 b$ and $c$ is much reduced. Indeed, a similar AOD belt is also observed from the original MODIS aerosol data and can be reduced with stringent cloud screening and quality assurance steps (Shi et al., 2011a). Although other factors could also contribute (Toth et al., 2013), cloud contamination is one of the sources for causing the elevated AOD belt over southern oceans (Shi et al., 2011a). The decrease in mean MISR AOD is more pronounced with the $F_{\mathrm{cc}}$ cloud filter at $F_{\mathrm{cc}}>80 \%$ compared with $F_{\mathrm{cc}}>20 \%$. Similar suppression in AOD is also found in high latitude northern oceans, which could be partially related to the broad regions of winter storm tracks. Over the west coast of North Africa, the AOD values are reduced in Fig. 3b and c compared with Fig. 3a (also seen from Fig. 3e and $f$, which were created to represent the differences between the self-QAed and the cloud-filtered MISR AODs). Thick aerosol plumes could be labeled as cloudy pixels and excluded from the cloud-filtered data sets. To further investigate if the reduction in AOD values over the regions mentioned above is caused by the thin cirrus cloud screening, the analysis was repeated using only the self-QAed MISR data that passed the cirrus cloud filter $\left(F_{\text {cirrus free }}=100 \%\right)$ for 2007 (Fig. 3d). Figure 3d shows that after the thin cirrus filter, the aerosol loadings over the focus area (west coast of North Africa) remain at a similar magnitude as Fig. 3a. Thus, 

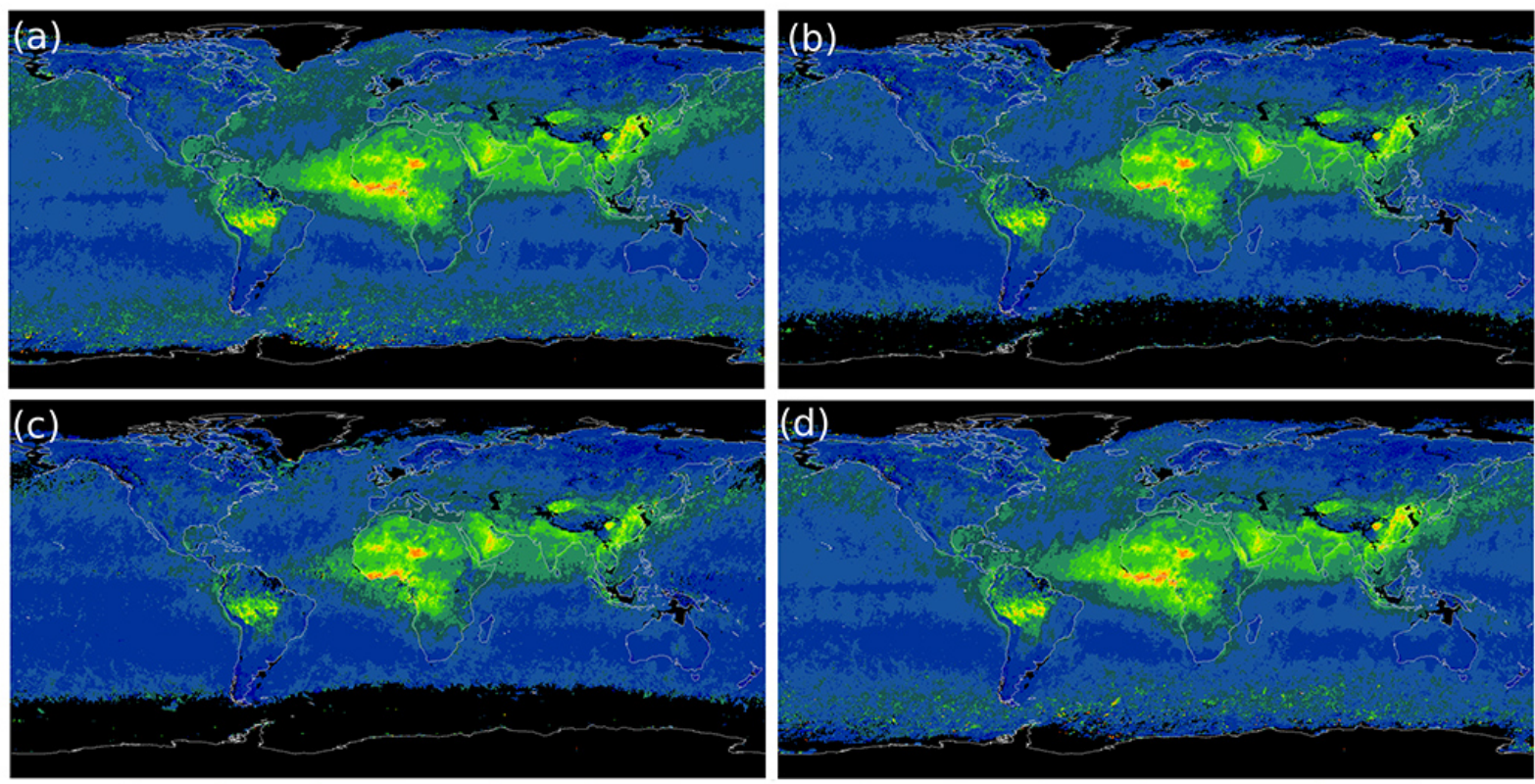

0
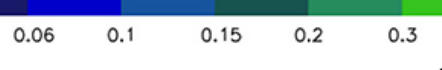

\section{MISR AOD $(0.558 \mu \mathrm{m})$}
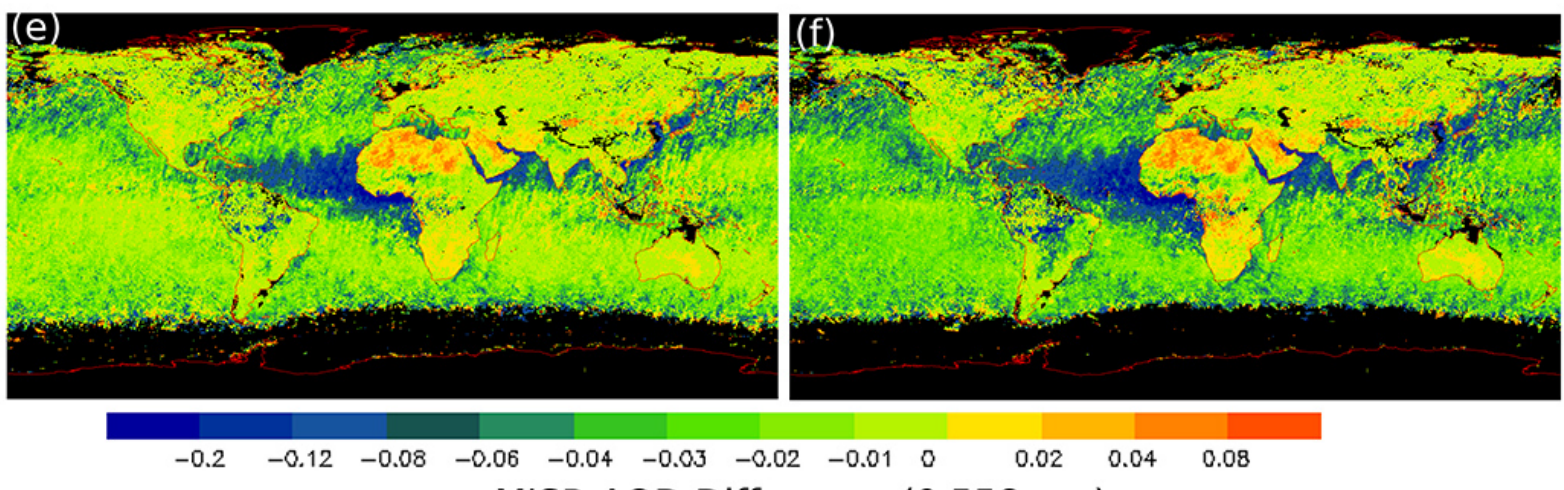

MISR AOD Difference $(0.558 \mu \mathrm{m})$

Figure 3. Spatial distribution of MISR AOD for the 2007 data set using the half-degree (lat/lon) gridded level 3 MISR AOD data. (a) for selfQAed MISR data, (b) for MISR data after applying the $F_{\mathrm{cc}}>20 \%$ and $F_{\text {cirrus }}$ free $=100 \%$ cloud filters, (c) for MISR data after applying the $F_{\text {cc }}>80 \%$ and $F_{\text {cirrus_free }}=100 \%$ cloud filters, $(\mathbf{d})$ for MISR data that passed the thin cirrus cloud filter $\left(F_{\text {cirrus_free }}=100 \%\right),(\mathbf{e})$ AOD plot of (b) minus (a), and (f) same as (e) but for (c) minus (a). Color contours progressing from cold to warm represent increasing AOD values with the black color representing regions with no data.

the weakened AOD features over the west coast of North Africa could be caused by applying the confident clear cloud filtering. Over the North African region, positive biases are found. The positive biases are introduced for two reasons: (1) the averaged AOD values are high over the region, and (2) some of the retrievals with AOD values less than 0.2 are removed by the MODIS cloud mask filtering, thus increasing the averaged AOD values. Also, a discontinuity is found between the over-ocean and over-land aerosol features along the west coast of North Africa (e.g., Fig. 3c). This discontinuity may be caused by the differences in the over-ocean versus over-land cloud screening algorithms from the MODIS cloud mask products.

\subsection{A longer-term study of cloud contamination in the MISR AOD data using $\boldsymbol{F}_{\text {cc }}$ data}

The monthly and zonal differences were evaluated between the MISR self-QAed AOD data and MISR AOD data sets with three different cloud screening methods for 2007. Figure 4 shows the monthly and zonal mean deviations from the self-QAed MISR AOD data for three data sets: (1-2) MISR AOD after applying the $F_{\mathrm{cc}}>20 \%$ and $80 \%$ filters combined with the thin cirrus cloud filter and 
(3) MISR AOD after applying the thin cirrus cloud filter $\left(F_{\text {cirrus_free }}=100 \%\right)$.

Figure 4a shows the monthly mean of MISR AOD minus the self-QAed AOD over global oceans. When compared to the self-QAed MISR AOD data, the cirrus-free $\left(F_{\text {cirrus_free }}=100 \%\right)$ data have mean MISR AOD values that are consistently 0.01 to 0.015 lower throughout the year. Although uncertainties exist in the MODIS $1.375 \mu \mathrm{m}$ cirrus detection method (Gao et al., 2002; Pierce et al., 2010), it is possible that thin cirrus cloud contamination is present in the MISR AOD data that could introduce a high bias of $\sim 0.01$ over global oceans. The thin cirrus related bias could reach 0.015-0.02 over oceans at mid- to high latitudes. Although not shown in this paper, a higher bias of $\sim 0.02$ was also found over Southeast Asia $\left(15^{\circ} \mathrm{S}\right.$ to $25^{\circ} \mathrm{N}, 90^{\circ} \mathrm{E}$ to $\left.160^{\circ} \mathrm{E}\right)$. The $F_{\mathrm{cc}}$ cloud screening method combined with the thin cirrus cloud filter introduces a year-round reduction in AOD of 0.02 to 0.06 depending on the thresholds, especially during May, June and July. Figure $4 \mathrm{~b}$ is similar to Fig. $4 \mathrm{a}$ but for the over-land case. When compared with self-QAed MISR AOD values, the thin cirrus cloud filter introduces a $\sim 0.005$ reduction in the averaged MISR AOD from February to August. The reduction is found to be around 0.005 to 0.015 when the $F_{\text {cc }}$ filters are applied.

Figure $4 \mathrm{c}$ and $\mathrm{d}$ show similar plots as Fig. $4 \mathrm{a}$ and $\mathrm{b}$ but for the differences in zonal mean AOD averaged every $5^{\circ}$ latitude bin. Over global oceans, the $F_{\mathrm{cc}}$ filters introduce larger reductions in AOD occurring from $0^{\circ}$ to $20^{\circ} \mathrm{N}$ and beyond $50^{\circ} \mathrm{S}$ with the largest reductions reaching 0.05 and 0.07 for $20 \%$ and $80 \% F_{\mathrm{cc}}$ cut off, respectively. After applying the $F_{\mathrm{cc}}$ filtering method, there is almost no MISR data available beyond $55^{\circ} \mathrm{S}$. Over-land, while compared with the selfQAed MISR zonal mean AOD values, reductions in MISR AOD are also found globally after applying the $F_{\mathrm{cc}}$ screening method.

\section{Recommendations and conclusion}

This study used collocated MODIS cloud mask products to evaluate potential cloud contamination in the MISR aerosol products. Major findings include

1. Cloud contamination exists in the MISR AOD data. Especially, thin cirrus cloud contamination introduces a possible mean AOD high bias of $\sim 0.01$ over global oceans and 0.015-0.02 over the mid- to high latitudes and Southeast Asia. This study suggests that additional cloud screening methods may be needed for using MISR aerosol products for future studies.

2. New MISR cloud screening methods such as the MISR CFF method (Witek et al., 2013) have been developed to reduce cloud contamination in the MISR aerosol retrievals. However, with the use of only visible and nearIR channels from MISR, such methods may still have (a) MISR AOD Monthly Mean Differences over Ocean

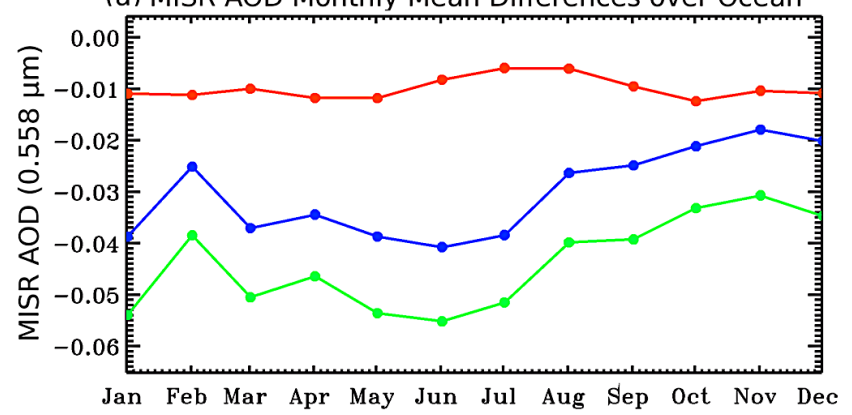

(b) MISR AOD Monthly Mean Differences over Land

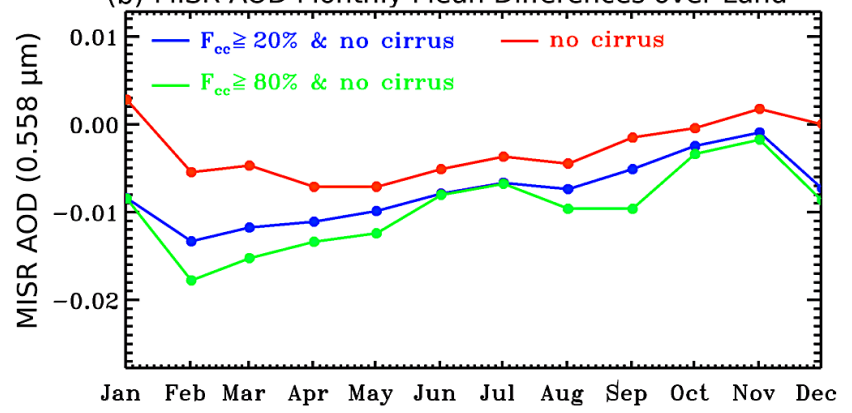

(c) MISR AOD Zonal Mean Differences over Ocean

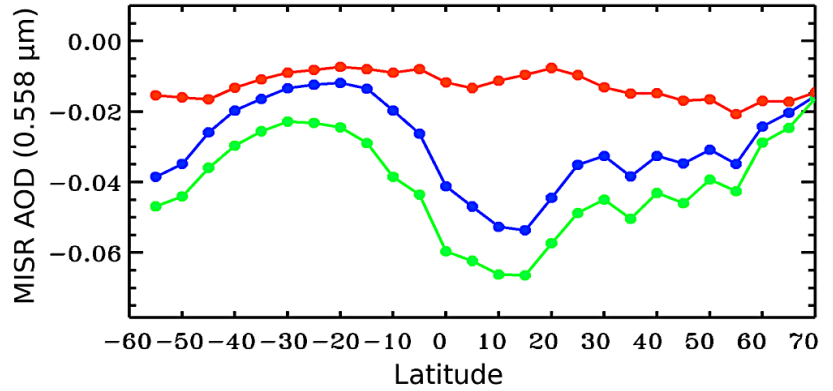

(d) MISR AOD Zonal Mean Differences over Land

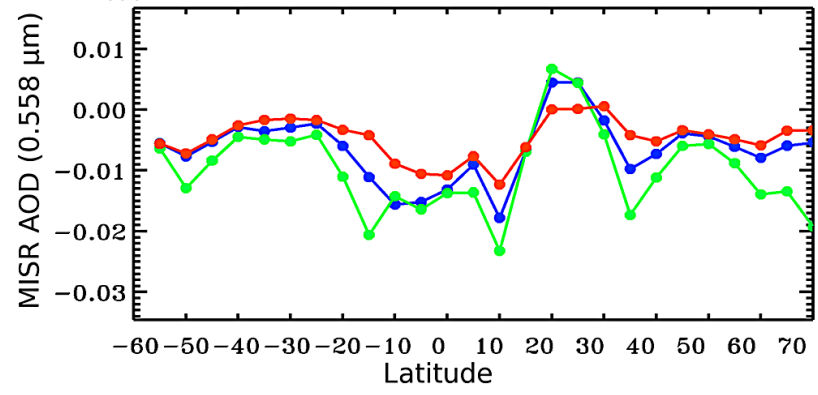

Figure 4. MISR AOD monthly and zonal mean deviations from the self-QAed MISR AOD for 2007 (minus self-QAed). (a) the overwater monthly mean, (b) the over-land monthly mean, (c) the overwater zonal mean, and (d) the over-land zonal mean. Three data sets are plotted, representing the data that passed the thin cirrus cloud filter $\left(F_{\text {cirrus free }}=100 \%\right)$ in red, data that passed $F_{\mathrm{cc}}>20 \%$ and $F_{\text {cirrus free }}=100 \%$ filters in blue, and data that passed $F_{\mathrm{cc}}>80 \%$ and $F_{\text {cirrus_free }}=100 \%$ filters in green. 
difficulty in identifying thin cirrus clouds, even while excluding a substantial fraction of the observations. The MODIS cloud masking data can be effectively used for reducing cloud contamination in the MISR aerosol retrievals, and is more effective in removing thin cirruscloud-contaminated cloudy MISR aerosol retrievals in comparison with cloud screening methods using only MISR observations.

3. Cloud masking using MODIS data introduces some potential problems. For example, it is possible that some of the high AODs are misidentified as cloudy pixels and are removed by the MODIS-based cloud filtering methods when stringent thresholds are used. The misidentification of thick dust and smoke scenes as cloud scenes by the MODIS cloud mask products, however, has a lesser effect on operational MODIS aerosol retrievals. For example, Levy et al. (2013) discussed an approach to restore thick dust and smoke scenes that are misidentified as clouds by the MODIS cloud screening method. A regional-based cloud screening method, such as a spatial variability test, may be needed for rescuing these misidentified heavy aerosol polluted scenes, through the combined used of MODIS and MISR data at the radiance level.

4. A closer look into the distance between the aerosol retrievals and cloud edge (Levy et al., 2013) may help users to choose the thresholds of the $F_{\mathrm{cc}}$ cloud filter for their applications. For example, MODIS Collection 6 DT aerosol products include a parameter called "Average Cloud Distance Land Ocean" that is helpful in solving this problem. It may also facilitate further investigation over the cloud contamination due to cloud 3-D effects, aerosol hydration over the high humidity environment, and the twilight zone issue.

5. This project demonstrated that data from one sensor (MODIS) can be applied to another (MISR) for the development of an improved product. Sensors that lack near-IR bands should consider this procedure when developing an aerosol product, for example Ocean and Land Colour Instrument (OLCI) on Sentinel-3. The farsighted developers of systems such as on Terra and within the A-train were correct in that the sensor combinations can result in improvements over any single sensor algorithm. This will pave the way for future algorithms, or even systems (such as NPP, Korean COMS, and EarthCARE), which require multiple sensors feeding single algorithms.

Acknowledgements. This research was funded by the Office of Naval Research Code 322 and the NASA Interdisciplinary Science Program. Yingxi Shi is funded by the NASA Earth and Space Science Fellowship Program. We also appreciate the MISR aerosol team, MODIS cloud mask team, the NASA Langley Atmospheric Science Data Center and NASA Goddard Space Flight Center for the MISR aerosol data and MODIS cloud mask data. We thank the AERONET program for establishing and maintaining the AERONET sites used in this study.

Edited by: O. Torres

\section{References}

Ackerman, S. A., Strabala, K. I., Menzel, W. P., Frey, R. A., Moeller, C. C., and Gumley, L. E.: Discriminating clear sky from clouds with MODIS, J. Geophys. Res. Atmos., 103, 32141-32157, 1998.

Ackerman, S. A., Holz, R. E., Frey, R. A., Eloranta, E. W., Maddux, B. C., and McGill, M.: Cloud detection with MODIS. Part II: Validation J. Atmos. Oceanic Technol., 25, 1073-1086, 2008.

Bull, M., Matthews, J., McDonald, D., Menzies, A., Moroney, C., Mueller, K., Paradise, S., and Smyth, M.: MISR Data Products Specifications Document, JPL D-13963, Revision S, 2010.

CCSP: Atmospheric aerosol properties and climate impacts, A report by the US Climate Change Science Program and the Subcommittee on Global Change Research, edited by: Chin, M. Kahn, R. A., and Schwartz, S. E., National Aeronautics and Space Administration, Washington, DC, USA, 128 pp., 2009.

Chew, B. N., Campbell, J. R., Reid, J. S., Giles, D. M., Welton, E. J., Salinas, S. V., and Liew, S. C.: Tropical cirrus cloud contamination in sun photometer data, Atmos. Environ., 45(37), 67246731, 2011.

Di Girolamo, L. and Davies, R.: A Band-Differenced Angular Signature technique for cirrus cloud detection, Geosci. Remote Sens. Trans., 32, 890-896, 1994.

Diner, D. J., Beckert, J. C., Reilly, T. H., Bruegge, C. J., Conel, J. E., Kahn, R. A., Martonchik, J. V., Ackerman, T. P., Davies, R., Gerstl, S. A., Gordon, H. R., Muller, J., Myneni, R., Sellers, P. J., Pinty, B., and Verstraete, M. M.: Multi-angle Imaging SpectroRadiometer (MISR) instrument description and experiment overview, Geosci. Remote Sens. Trans., 36, 1072-1087, 1998.

Diner, D. J., Abdou, W. A., Ackerman, T. P., Crean, K., Gordon, H. R., Kahn, R. A., Martonchik, J. V., McMuldroch, S., Paradise, S. R., Pinty, B., Verstraete, M. M., Wang, M., and West, R. A.: Level 2 aerosol retrieval algorithm theoretical basis, Jet Propulsion Laboratory, California Institute of Technology, 2001.

Frey, R. A., Acherman, S. A., Liu, Y., Strabala, K. I., Zhang, H., Key, J. R., and Wang, X.: Cloud detection with MODIS, Part I: Improvements in the MODIS cloud mask for Collection 5, J. Atmos. Oceanic Technol., 25, 1057-1072, 2008.

Gao, B. C. and Kaufman, Y. J.: Water vapor retrievals using Moderate Resolution Imaging Spectroradiometer (MODIS) near-infrared channels, J. Geophys. Res., 108, 4389, doi:10.1029/2002JD003023, 2003.

Gao, B. C., Yang, P., Han, W., Li, R., and Wiscombe, W.: An algorithm using visible and $1.38 \mu \mathrm{m}$ channels to retrieve cirrus cloud reflectances from aircraft and satellite data, IEEE T. Geosci. Remote, 40, 1659-1668, doi:10.1109/TGRS.2002.802454, 2002.

Holben, B. N., Eck, T. F., Slutsker, I., Tanré, D., Buis, J. P., Set- zer, A., Vermote, E., Reagan, J. A., Kaufman, Y. J., Nakajima, T., Lavenu, F., Jankowiak, I., and Smirnov, A.: A ERONET- A Fed- 
erated Instrument Network and Data Archive for Aerosol Characterization, Remote Sens. Environ., 66, 1-16, 1998.

Hyer, E. J., Reid, J. S., and Zhang, J.: An over-land aerosol optical depth data set for data assimilation by filtering, correction, and aggregation of MODIS Collection 5 optical depth retrievals, Atmos. Meas. Tech., 4, 379-408, doi:10.5194/amt-4-379-2011, 2011.

Kahn, R. A., Gaitley, A. B., Martonchik, J., Diner, D., Crean, K., and Holben, B. N.: MISR global aerosol optical depth validation based on two years of coincident AERONET observations, J. Geophys. Res., 110, D10S04, doi:10.1029/2004JD004706, 2005.

Kahn, R. A., Li, W.-H., Moroney, C., Diner, D. J., Martonchik, J. V., and Fishbein, E.: Aerosol source plume physical characteristics from space-based multiangle imaging, J. Geophys. Res., 112, D11205, doi:10.1029/2006JD007647, 2007.

Kahn, R. A., Nelson, D. L., Garay, M. J., Levy, R. C., Bull, M. A., Diner, D. J., Martonchik, J. V., Paradise, S. R., Hansen, E. G., and Remer, L. A.: MISR aerosol product attributes and statistical comparisons with MODIS, Geosci. Remote Sens. Trans., 47, 4095-4114, 2009.

Kahn, R. A., Gaitley, B. J., Garay, M. J., Diner, D. J., Eck, T. F., Smirnov, A., and Holbem, B. N.: Multiangle Imaging SpectroRadiometer global aerosol product assessment by comparison with Aerosol Robotic Network, J. Geophys. Res., 115, D23209, doi:10.1029/2010JD014601, 2010.

Levy, R. C., Mattoo, S., Munchak, L. A., Remer, L. A., Sayer, A. M., Patadia, F., and Hsu, N. C.: The Collection 6 MODIS aerosol products over land and ocean, Atmos. Meas. Tech., 6, 29893034, doi:10.5194/amt-6-2989-2013, 2013.

Martonchik, J. V., Diner, D. J., Kahn, R. A., Ackerman, T. P., Verstraete, M. M., Pinty, B., and Gordon, H. R.: Techniques for the retrieval of aerosol properties over land and ocean using multiangle imaging, Geosci. Remote Sens. Trans., 36, 1212-1227, 1998.

Martonchik, J. V., Diner, D. J., Crean, K. A., and Bull, M. A.: Regional aerosol retrieval results from MISR, Geosci. Remote Sens. Trans., 40, 1520-1531, 2002.

Martonchik, J. V., Kahn, R. A., and Diner, D. J.: Retrieval of Aerosol Properties over Land Using MISR Observations, in: Satellite Aerosol Remote Sensing Over Land, edited by: Kokhanovsky, A. A. and de Leeuw, G., Springer, Berlin, 267293, 2009.

Pierce, J. R., Kahn, R. A., Davis, M. R., and Comstock, J. M.: Detecting thin cirrus in Multiangle Imaging Spectroradiometer aerosol retrievals, J. Geophys. Res. Atmos., V115, D8201, doi:10.1029/2009JD013019, 2010.

Remer, L. A., Kaufman, Y. J., Tanre, D., Mattoo, S., Chu, D. A., Martins, J. V., Li, R. R., Ichoku, C., Levy, R. C., Kleidman, R. G., Eck, T. F., Vermote, E., and Holben, B. N.: The MODIS aerosol algorithm, products and validation. J. Atmos. Sci., 62, 947-973, 2005

Sassen, K. and Cho, B. S.: Subvisual-thin cirrus lidar dataset for satellite verification and climatological research, J. Appl. Meteorol., 31, 1275-1285, 1992.
Shi, Y., Zhang, J., Reid, J. S., Holben, B., Hyer, E. J., and Curtis, C.: An analysis of the collection 5 MODIS over-ocean aerosol optical depth product for its implication in aerosol assimilation, Atmos. Chem. Phys., 11, 557-565, doi:10.5194/acp-11-557-2011, 2011a.

Shi, Y., Zhang, J., Reid, J. S., Hyer, E. J., Eck, T. F., Holben, B. N., and Kahn, R. A.: A critical examination of spatial biases between MODIS and MISR aerosol products - application for potential AERONET deployment, Atmos. Meas. Tech., 4, 2823 2836, doi:10.5194/amt-4-2823-2011, 2011 b.

Smirnov, A., Holben, B. N., Slutsker, I., Giles, D. M., McClain, C. R., Eck, T. F., Sakerin, S. M., Macke, A., Croot, P., Zibordi, G., Quinn, P. K., Sciare, J., Kinne, S., Harvey, M., Smyth, T. J., Piketh, S., Zielinski, T., Proshutinsky, A., Goes, J. I., Nelson, N. B., Larouche, P., Radionov, V. F., Goloub, P., Moorthy, K. K., Matarrese, R., Robertson, E. J., and Jourdin, F.: Maritime Aerosol Network as a component of Aerosol Robotic Network, J. Geophys. Res., 114, D06204, doi:10.1029/2008JD011257, 2009.

Tackett, J. L. and Girolamo, L. D.: Enhanced aerosol backscatter adjacent to tropical trade wind clouds revealed by satellite-based lidar, Geophys. Res. Lett., 36, L14804, doi:10.1029/2009GL039264, 2009.

Toth, T. D., Zhang, J., Campbell, J. R., Reid, J. S., Shi, Y., Johnson, R. S., Smirnov, A., Vaughan, M. A., and Winker, D. M.: Investigating Enhanced Aqua MODIS Aerosol Optical Depth Retrievals over the Mid-to-High Latitude Southern Oceans through Intercomparison with Co-Located CALIOP, MAN, and AERONET Datasets. J. Geophys. Res. Atmos., 118, 4700-4714, doi:10.1002/jgrd.50311, 2013.

Witek, M. L., Garay, M. J., Diner, D. J., and Smirnov, A.: Aerosol optical depths over oceans: a view from MISR retrievals and collocated MAN and AERONET in-situ observations, J. Geophys. Res. Atmos., 118, 12-620, 2013.

Zhang, J. and Reid., J. S.: MODIS Aerosol Product Analysis for Data Assimilation: Assessment of Level 2 Aerosol Optical Thickness Retrievals, J. Geophys. Res.-Atmos., 111, D22207, doi:10.1029/2005JD006898, 2006.

Zhang, J. and Reid, J. S.: A decadal regional and global trend analysis of the aerosol optical depth using a data-assimilation grade over-water MODIS and Level 2 MISR aerosol products, Atmos. Chem. Phys., 10, 10949-10963, doi:10.5194/acp-1010949-2010, 2010.

Zhang, J., Reid, J. S., and Holben, B. N.: An analysis of potential cloud artifacts in MODIS over ocean aerosol optical thickness products, Geophys. Res. Lett., 32, L15803, doi:10.1029/2005GL023254, 2005.

Zhao, T. X. P., Chan, P. K., and Heidinger, A. K.: A Global Survey of the Effect of Cloud Contamination on the Aerosol Optical Thickness and Its Long-term Trend Derived from Operational AVHRR Satellite Observations. J. Geosphys. Res.-Atmos., 118, 2849-2857, doi:10.1002/jgrd.50278, 2013. 